\title{
Anthraquinones production, hydrogen peroxide level and antioxidant vitamins in Morinda elliptica cell suspension cultures from intermediary and production medium strategies
}

\begin{abstract}
The effects of medium strategies [maintenance $(\mathrm{M})$, intermediary $(\mathrm{G})$, and production $(\mathrm{P})$ medium] on cell growth, anthraquinone (AQ) production, hydrogen peroxide $(\mathrm{H} 2 \mathrm{O} 2)$ level, lipid peroxidation, and antioxidant vitamins in Morinda elliptica cell suspension cultures were investigated. These were compared with third-stage leaf and 1-month-old callus culture. With P medium strategy, cell growth at $49 \mathrm{~g} \mathrm{l}-1$, intracellular AQ content at $42 \mathrm{mg} \mathrm{g}-1 \mathrm{DW}$, and $\mathrm{H} 2 \mathrm{O} 2$ level at 9 mol g-1 FW medium were the highest as compared to the others. However, the extent of lipid peroxidation at $40.4 \mathrm{nmol}$ g-1 FW and total carotenoids at 13.3 mg g-1 FW for cultures in $\mathrm{P}$ medium were comparable to that in the leaf, which had registered sevenfold lower AQ and 2.2-fold lower H2O2 levels. Vitamin C content at 30-120 $\mathrm{g}$ g-1 FW in all culture systems was almost half the leaf content. On the other hand, vitamin E content was around 400-500 g g-1 FW in 7-day-old cultures from all medium strategies and reduced to 50-150 g g-1 FW on day 14 and 21; as compared to $60 \mathrm{~g} \mathrm{~g}-1 \mathrm{FW}$ in callus and $200 \mathrm{~g}$ g- $1 \mathrm{FW}$ in the leaf. This study suggests that medium strategies and cell growth phase in cell culture could influence the competition between primary and secondary metabolism, oxidative stresses and antioxidative measures. When compared with the leaf metabolism, these activities are dynamic depending on the types and availability of antioxidants.
\end{abstract}

Keyword: Morinda elliptica, Cell suspension culture, Anthraquinones, Antioxidant, Vitamins, Hydrogen peroxide, Lipid peroxidation 